\title{
Molecular Docking Studies of Myricetin and Its Analogues against Human PDK-1 Kinase as Candidate Drugs for Cancer
}

\author{
Shalini Singh, Pradeep Srivastava* \\ School of Biochemical Engineering IIT (BHU), Varanasi, India \\ Email: ${ }^{*}$ pksrivasatava.bce@itbhu.ac.in
}

Received 12 May 2015; accepted 27 June 2015; published 30 June 2015

Copyright (C) 2015 by authors and Scientific Research Publishing Inc.

This work is licensed under the Creative Commons Attribution International License (CC BY).

http://creativecommons.org/licenses/by/4.0/

(c) (7) Open Access

\begin{abstract}
Phosphoinositide-dependent protein kinase-1 (PDK1), the class of serine threonine kinase, is a master regulator of the AGC family of kinases. It is a main component of the PI3K pathway. As it is reported that this pathway is most commonly, and this pathway is the most commonly deregulated among many cancers. So designing a selective inhibitor of PDK1 may have the efficacy as an anticancer agent. Herein, we describe our work focused on the structure based on screening of $95 \%$ similar analogues of Myricetin deposited in PubChem database as earlier studies have been suggested that myricetin acts as an anti cancer agent. Further molecular docking as well as the in silico ADMET studies are incorporated on these compounds to evaluate the binding and pharmacokinetic properties of these compounds. Due to low oral bioavailability, clinical use of myricetin is limited. Therefore this study is an attempt towards screening of structurally similar better compounds as compare with myricetin which can act as better inhibitor against PDK-1.
\end{abstract}

\section{Keywords}

Myricetin, PDK-1, ADMET, Docking, Analogues

\section{Introduction}

Protein kinases are critical components of cellular signal transduction cascades [1]. Over 500 protein kinases in the human genome have been reported till date and they are considered as the second largest group of drug targets [2]-[3]. Phosphoinositide-dependent kinase-1 (PDK-1), a $63 \mathrm{kDa}$ serine/threonine kinase, is a major player in the PI3-kinase signaling pathway that regulates gene expression, cell cycle, growth and proliferation [4]-[11].

"Corresponding author.

How to cite this paper: Singh, S. and Srivastava, P. (2015) Molecular Docking Studies of Myricetin and Its Analogues against Human PDK-1 Kinase as Candidate Drugs for Cancer. Computational Molecular Bioscience, 5, 20-33. 
PDK-1 is also termed as the "master kinase" because it phosphorylates highly conserved serine or threonine residues in the T-loop (or activation loop) of numerous AGC kinases, including PKB/AKT, PKC, p70S6K, SGK, and PDK-1 itself [12]. Although precise regulatory mechanisms may vary in the case of PKB/AKT, yet activation by PDK-1 is critically dependent upon prior PI3 kinase activation and the presence of phosphatidylinositol-(3,4,5)-triphosphate (PIP3). A significant proportion (40\% - 50\%) of all tumors involves mutations in PIP33-phosphatase (PTEN) [13]-[15], which results in elevated levels of PIP3 and enhances an activation of PKB/AKT, p70S6K, and SGK. The inhibitors of PDK-1 can potentially provide valuable therapeutic agents for the treatment of cancer.

It is confirmed by the previous study that Myricetin acts as a putative inhibitor for several cancer. The presented work is an attempt to screen 95\% similar compounds deposited in Pubchem database. Several computational methods like Lipinski filter molecular docking and in silico ADMET study have been incorporated on the screen compounds to predict these molecules behavior as a putative future drug for cancer treatment.

\section{Material and Methods}

\subsection{Chemical Similarity Search}

The two dimensional chemical structure of natural flavonoid Myricetin (CID5281672) was retrieved from the NCBI PubChem database (http://www.pubchem.ncbi.nlm.nih.gov) and similarity search was performed on the chemical compounds deposited in the Pubchem database to retrieve the related compound and analogues. The search parameters were set at 95\% similarity. 2D structures of all screened compounds were downloaded from pubchem database. The whole methodology used for study is shown in Figure 1.

\subsection{Preparation of Ligands}

The three dimensional format of all filtered compounds were downloaded from Pubchem database in .sd file formt. Subsequently CharMM [16] based force field was applied and further subjected to single step energy minimization using steepest descent method for 500 steps at RMS gradient of 0.01 .
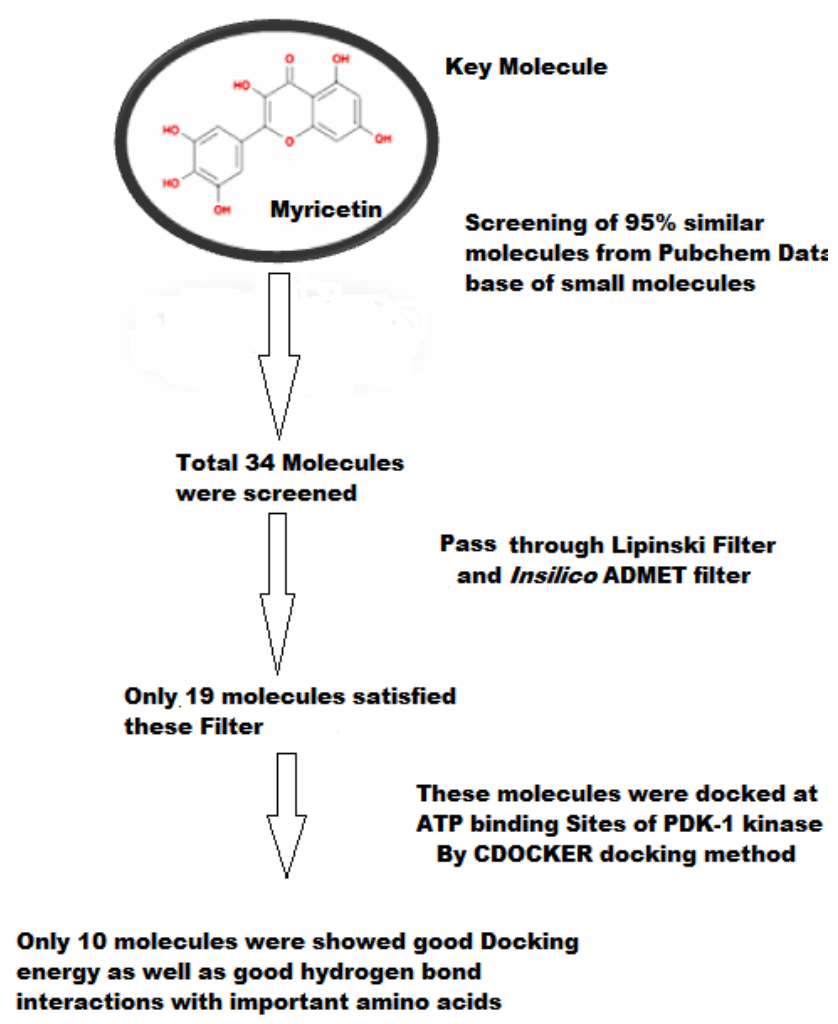

Figure 1. Flow diagram of complete methodology used for study. 


\subsection{Minimization}

Energy minimization is an important step in molecular modeling of proteins/peptides. It was used to compute the equilibrium configuration of molecules. Energy minimization methods can be divided into different classes depending on the order of the derivative used for locating a minimum on the energy surface.

\subsubsection{Steepest Descent Method}

The steepest descent method uses the first derivative to determine the direction towards the minimum. It is not particularly efficient because it must be combined with a line search to determine the step size. The line search uses the direction vector obtained from the first derivative of the potential function to find the optimum step size along this vector direction. Once this local minimum along the direction of the derivative is found the step can be taken. The next derivative will be orthogonal to the first. A line search is requires several function evaluations, however, in order to determine the optimum step size. This technique is robust and is used to minimize initially when the structure is far from the minimum configuration.

\subsubsection{Conjugate Gradient Methods}

More efficient minimization can be obtained using conjugate gradients algorithms. The conjugate gradient technique uses information from previous first derivatives to determine the optimum direction for a line search.

\subsection{Lipinski Filter}

The drug likeliness properties of all the retrieved compounds were evaluated by Lipinski drug filter [17] implemented in Accelrys Discovery Studio 2.5 [18]. This rule basically describes those molecular properties which is essential for a drug's pharmacokinetics in the human body and also provides the information concerning the deployment of the ligands as a drug molecule.

\subsection{Protein Preparation}

The X ray crystal structure of PDK-1 (PDB id 1UU7) [19] taken in this study was retrieved from protein data bank (http://www.pdb.org), all the HETATMS were removed. Further the protein was subjected to two steps energy minimization to remove the bad steric clashes using steepest descent and conjugate gradient methods for 1000 steps at RMS gradient of 0.1 and 0.05 respectively. During the energy minimization process the backbone and side chain were fixed by applying the fixed atom constraint, and only hydrogen atoms were minimized. The CharmM force field was applied to the receptors. Fixed atom constrained was removed after the minimization. The receptor protein is divided into the protein part and crystal ligand part. The protein part was only selected and selections were made to "define selected molecule as receptor" under define and edit binding site, sub panel of the "Tool panel", where in, the protein is marked as receptor molecule. By selecting only the ligand part and further clicking on "Define sphere from selection" so that the crystal ligand can be used to define the binding site of 15 Angstroms on the receptor molecule. This 'input receptor molecule' is used as input parameter in the CDOCKER [20] protocol parameter explorer.

\subsection{Molecular Docking Simulation}

Molecular docking was performed by the CDOCKER docking method implemented in Discovery Studio 2.5. CDOCKER is a simulated annealing based molecular docking method. In this docking method ligands are treated as fully flexible while protein is kept rigid. The minimized structure of all compounds was used as input ligand in the protocol explorer of CDOCKER. Each of them is given as input in another parameter meant for 'input ligands' and the protocol are run as many times as the number of inhibitors are selected for the experiment. The various conformations for ligand in this procedure were generated by using molecular dynamics. The generated initial structures for the ligand may be further refined using simulated annealing. The CDOCKER energy (-(protein-ligand interaction energies)) of best configuration docked into the receptor of all the selected natural inhibitors, which were calculated and compared with that of interacting residues at active site region with the crystallized inhibitors, PDK-1 kinase protein. Binding energy of protein and ligands were calculated by following calculation:

$$
\mathrm{E}_{\text {binding }}=\mathrm{E}_{\text {complex }}-\left(\mathrm{E}_{\text {receptor }}+\mathrm{E}_{\text {ligand }}\right)
$$




\subsection{ADME Study}

Insilico ADMET studies have been done by using the ADMET protocol implemented in D.S 2.5 (Accelrys Discovery studio software). In silico ADME studies solely depend on the chemical structure of molecules. In silico ADMET properties such as ADMET BBB level [21], absorption, aqueous solubility [22] hepatotoxicity [23], CYP2D6 [24], AlogP98 [25] and PSA [26] are studied for the standard compounds from standard data set and further evaluation has been done on test set compounds. A standard ADMET model is generated which predict the human intestinal absorption (HIA) after oral administration of the inhibitors tested. The intestinal absorption model includes 95\% and 99\% confidence ellipses in the ADMET_PSA_2D and ADMET_AlogP98 plane. There are four prediction levels for the absorption of compounds as good (0), moderate (1), poor (2) and very poor (3). These levels are defined by the 95\% (red line) and 99\% (green line) confidence ellipsoids .The upper limit of PSA_2D value for the 95\% confidence ellipsoid is at 131.62, while the upper limit of PSA_2D value for the 99\% confidence ellipsoid is at 148.12 .

\subsection{Toxicity Prediction}

Toxicity profiling of all selected ligands were performed by employing Toxicity prediction—extensible protocol implemented in Accelrys discovery studio 2.5 .

Toxicity prediction profile includes screening for aerobic biodegradability, developmental toxicity potentials, AMES mutagenicity, carcinogenicity \& skin irritancy [27].

\section{Results and Discussions}

\subsection{Drug Likeness Study}

Lipinski filter is used to study the drug likeness of all screened molecules. Figure 2 represent structural overlapping of myricetin and 95\% similar analogues. The Molecular properties of all the compounds calculated by lipinski were tabulated in Table 1. Table 1 showed that all the screened analogues were satisfied the lipinski rule of five for being used as a probable drug in future. The 3 dimensional correlation plots among molecular weight, Alog P and polar surface area were represented in Figure 3.

\subsection{ADME Study}

Most of drug failures have been reported in early and late pipeline stage due to undesired pharmacokinetics and toxicity problems. If these issues can be addressed early, it would be extremely advantageous for the drug discovery process. The use of in silico methods to predict ADMET properties is projected as a first step in this direction to analyze the novel chemical entities to prevent wasting time on lead candidates that would be toxic or

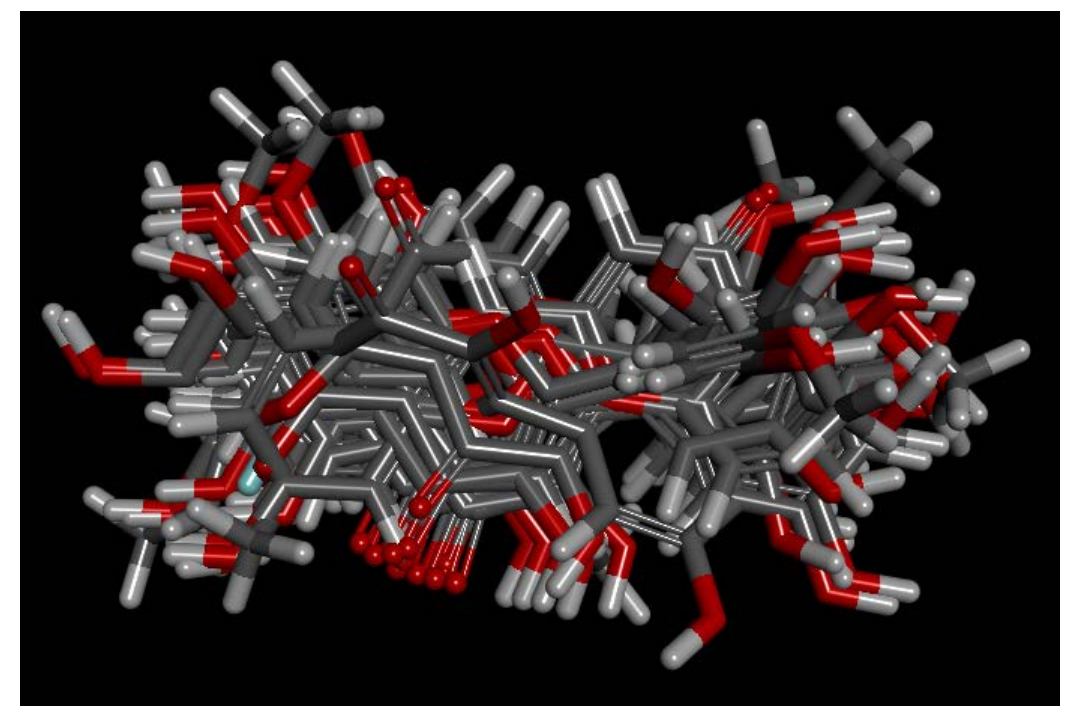

Figure 2. Myricetin and screened 95\% similar structural analogues. 


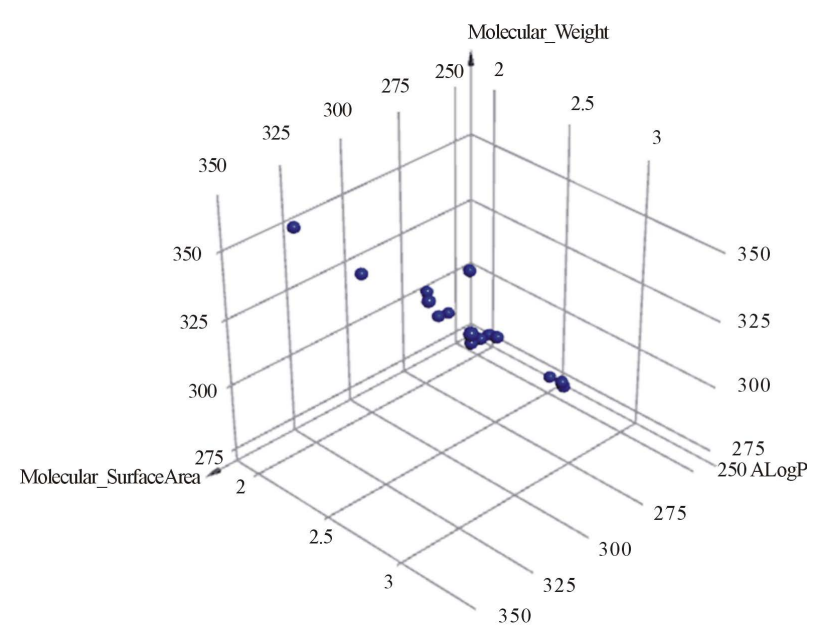

Figure 3. Represent the 3D plot of Myricetin and analogues Representing the correlation of Mol. Weight/Alog P/Molecular_surface Area.

Table 1. Molecular properties of Myricetin and analogues molecules.

\begin{tabular}{|c|c|c|c|c|c|c|c|}
\hline Compounds & ALogP & $\begin{array}{l}\text { Molecular } \\
\text { Weight }\end{array}$ & Num_Rings & $\begin{array}{l}\text { Num Aromatic } \\
\text { Rings }\end{array}$ & $\begin{array}{l}\text { Num_H } \\
\text { Acceptor }\end{array}$ & $\begin{array}{c}\text { Num_H } \\
\text { Donar }\end{array}$ & $\begin{array}{c}\text { Molecular } \\
\text { Fractional Polar } \\
\text { Surface area }\end{array}$ \\
\hline CID_5281701 & 1.926 & 302.236 & 3 & 2 & 7 & 5 & 0.47 \\
\hline CID_10517292 & 1.872 & 286.236 & 3 & 2 & 6 & 4 & 0.419 \\
\hline CID_10636768 & 2.731 & 284.263 & 3 & 2 & 5 & 3 & 0.335 \\
\hline CID_13964548 & 2.619 & 314.289 & 3 & 2 & 6 & 2 & 0.289 \\
\hline CID_13964550 & 2.394 & 300.263 & 3 & 2 & 6 & 3 & 0.349 \\
\hline CID_24721178 & 1.872 & 286.236 & 3 & 2 & 6 & 4 & 0.419 \\
\hline CID_5281697 & 2.168 & 286.236 & 3 & 2 & 6 & 4 & 0.419 \\
\hline CID_5281953 & 1.839 & 346.288 & 3 & 2 & 8 & 4 & 0.391 \\
\hline CID_5315126 & 3.487 & 370.353 & 3 & 2 & 7 & 5 & 0.361 \\
\hline CID_5318214 & 2.394 & 300.263 & 3 & 2 & 6 & 3 & 0.349 \\
\hline CID_5320287 & 2.081 & 330.289 & 3 & 2 & 7 & 3 & 0.342 \\
\hline CID_5322065 & 2.41 & 270.237 & 3 & 2 & 5 & 3 & 0.358 \\
\hline CID_5393164 & 2.168 & 286.236 & 3 & 2 & 6 & 4 & 0.419 \\
\hline CID_57402278 & 2.728 & 344.315 & 3 & 2 & 7 & 4 & 0.364 \\
\hline CID_6477684 & 2.878 & 296.274 & 3 & 2 & 5 & 3 & 0.321 \\
\hline CID_6477685 & 2.636 & 312.274 & 3 & 2 & 6 & 4 & 0.377 \\
\hline CID_66574000 & 2.283 & 322.217 & 3 & 2 & 6 & 4 & 0.393 \\
\hline CID_9839293 & 2.098 & 300.263 & 3 & 2 & 6 & 3 & 0.349 \\
\hline Myricetin & 1.388 & 318.23 & 3 & 2 & 8 & 6 & 0.532 \\
\hline
\end{tabular}

metabolized by the body into an inactive form and unable to cross membranes, and the results of such analysis are herein reported in Table 2 together with a biplot (Figure 4) and discussed. The pharmacokinetic properties of all the molecules under study were predicted by six predefined ADMET models presented in Discovery Studio 2.5 program. After examine the biplot of the ADMET study, it was observed the biplot represents two analogous at $95 \%$ and $99 \%$ confidence ellipses corresponding to HIA and BBB models. PSA (polar surface area) is an 
ADMET_AlogP98 vs.ADMET_PSA_2D

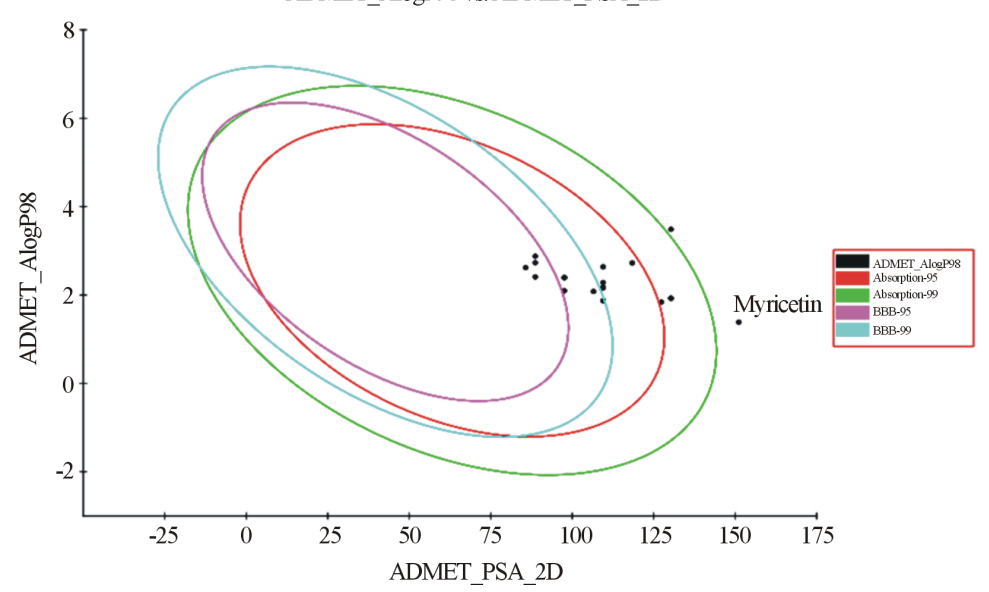

Figure 4. ADMET Description plot of Myricetin and their analogues.

useful parameter for prediction of drug transportation in different part of the body. The predefined models usually neglect the effect of other descriptors. The drug transportation and permeability has been demonstrated by PSA (plasma surface area). The cell membrane phospholipidbilayer is able to form hydrophobic and hydrophilic interactions as suggested by the fluid mosaic model, so lipophilicity is also play an essential property for drug designing and development. Lipophilicity of any compound could be expressed as the logarithms of the partition coefficient between $n$-octanol and water (log P). Thus the all the information about $\mathrm{H}$-bonding could be govern by both PSA as well as log P calculation. Therefore in all model a plot between descriptors AlogP98 and PSA 2D at $95 \%$ and $99 \%$ confidence ellipses was considered for the precise prediction for the cell permeability of compounds. The region of $95 \%$ confidence ellipse depicts the chemical area well-absorbed compounds $(\geq 90 \%)$ 95 out of 100 times. Whereas $99 \%$ is a confidence ellipse depicts chemical area of those compounds which having excellent absorption through cell membrane. Compound having an optimum cell permeability should follow the criteria (PSA $<140 \AA^{2}$ and AlogP98 $<5$ ) as describe in the model. The results show that all the compounds except myricetin (151.23 A2) showed polar surface area (PSA) $<140 \AA^{2}$. It was shown in Figure 5(d) that all the compounds have AlogP98 value $<5$ at 99\% and 95\% confidence ellipse for both HIA and BBB. Table 2 shows that majority of the compounds have low or undefined values for BBB penetration levels (levels 3 and 4) without any violation. The aqueous solubility also plays a critical role in the bioavailability of the candidate drugs, myricetin and compound CID_5315126 having low aqueous solubility level (level 2 and level 3 respectively) as shown in Table 2 while others having good aqueous solubility level shows that analogues are more soluble. Solubility plays an important role in bioavailability of any drug. For any drug to be absorbed properly it should be more or less completely soluble in water. Further, all compounds have been predicted to have hepatotoxicity level of 1 . It means the Myricetin and their screened analogues have some liver toxicity. Further studies are necessary to determine the dose level. Similarly, among all screened compounds only few compounds are showed satisfactory results respect to CYP2D6 liver (with reference to Table 2), suggesting that a these compounds are non inhibitors of CYP2D6 . This indicates that these analogues (CID_5281701, CID_13964550, CID_24721178, CID_5315126, CID_6477685 and CID_66574000) are well metabolized in Phase-I metabolism.CYP2D6 is class of Cytochrome 450 class of enzyme, is play an essential role in drug metabolism.

\subsection{Toxicity Prediction}

Insilico toxicity profile of all selected ligands was shown in Table 3. None of the compounds were show the Ames mutagenecity, skin sensitivity, and rodent carcinogenicity. But only few compounds were pass the DTP (developmental toxicity potential parameters). The following results depicts that those compounds which were passed the all parameters of toxicity prediction parameters can be developed as future drug for cancer treatment.

\subsection{Molecular Docking Results}

Myricetin (3,5,7-Trihydroxy-2-(3,4,5-trihydroxyphenyl)-4-chromenone), is natural occurring flavanol [28] [29] 


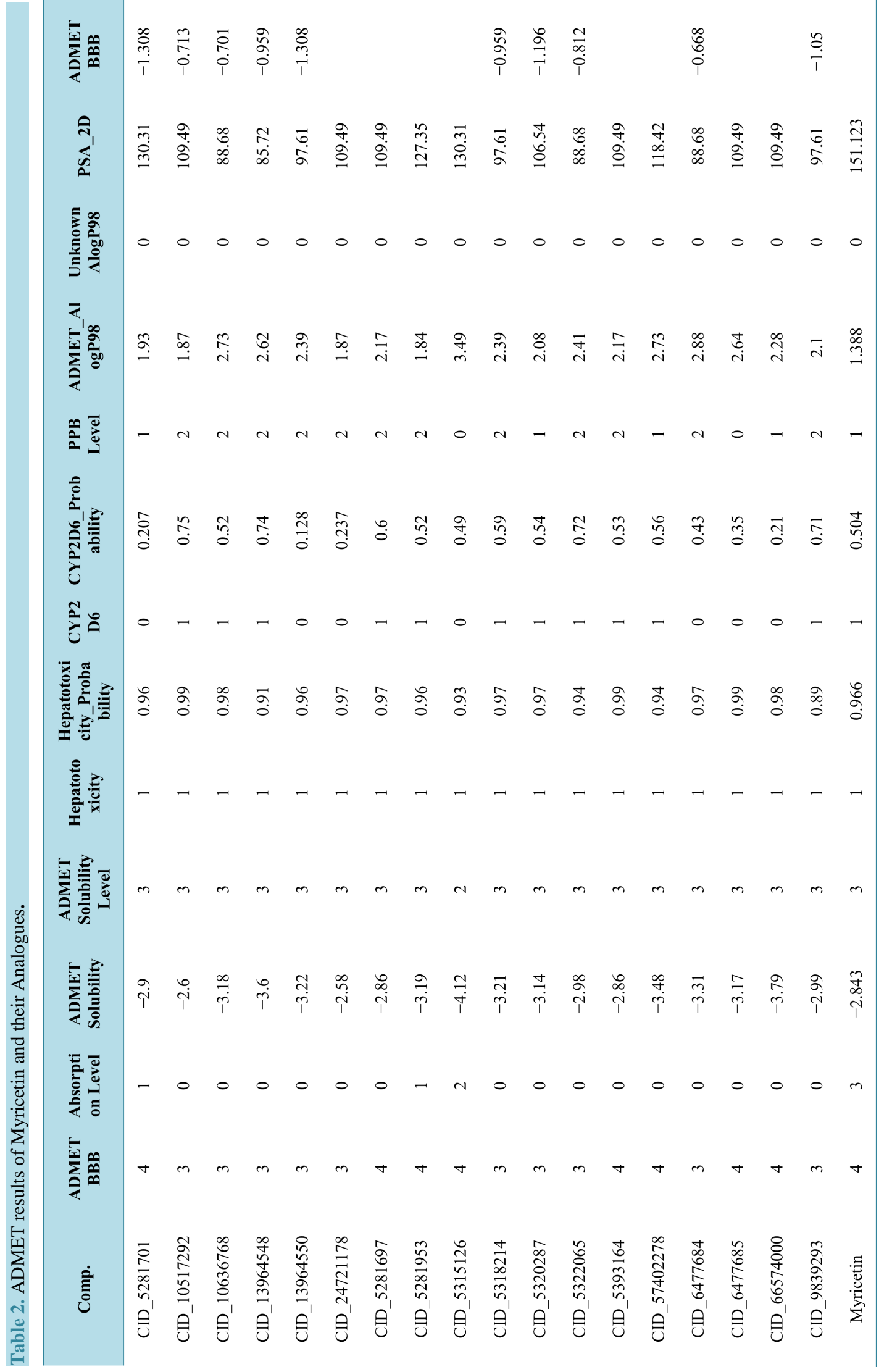




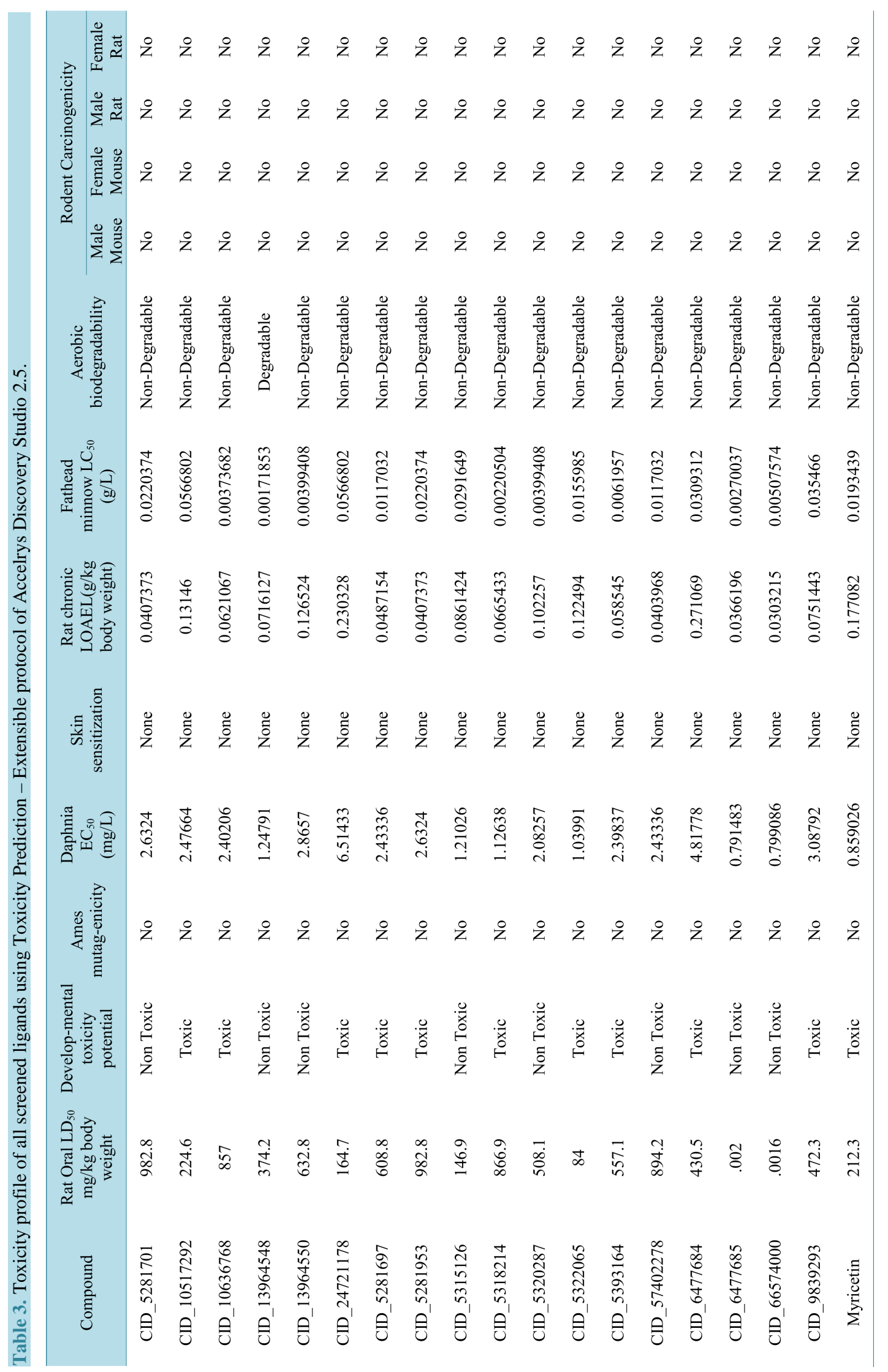




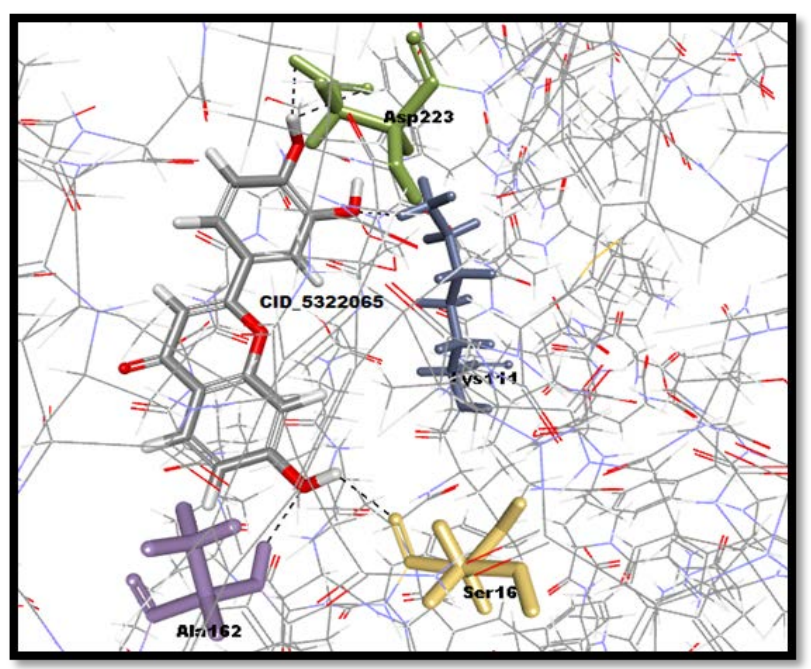

(a)

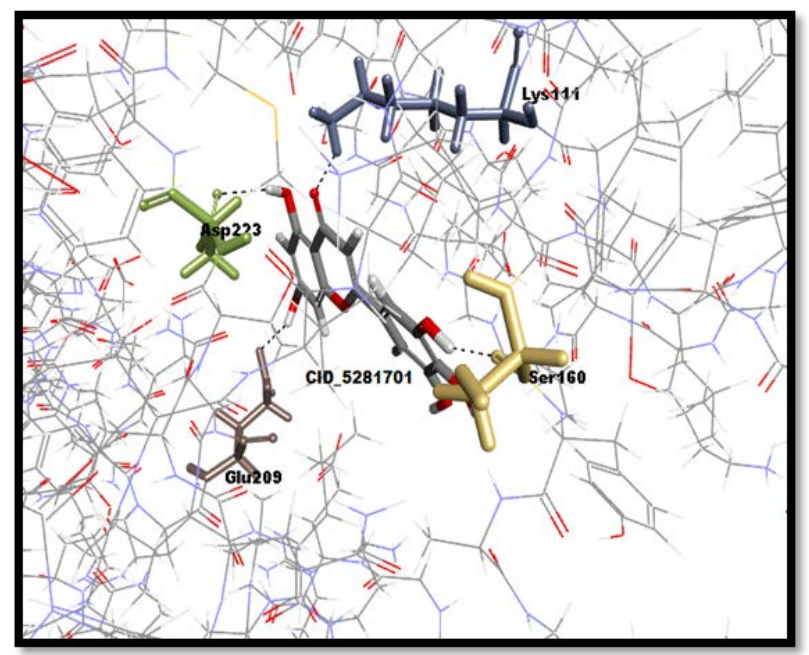

(b)



(c) 


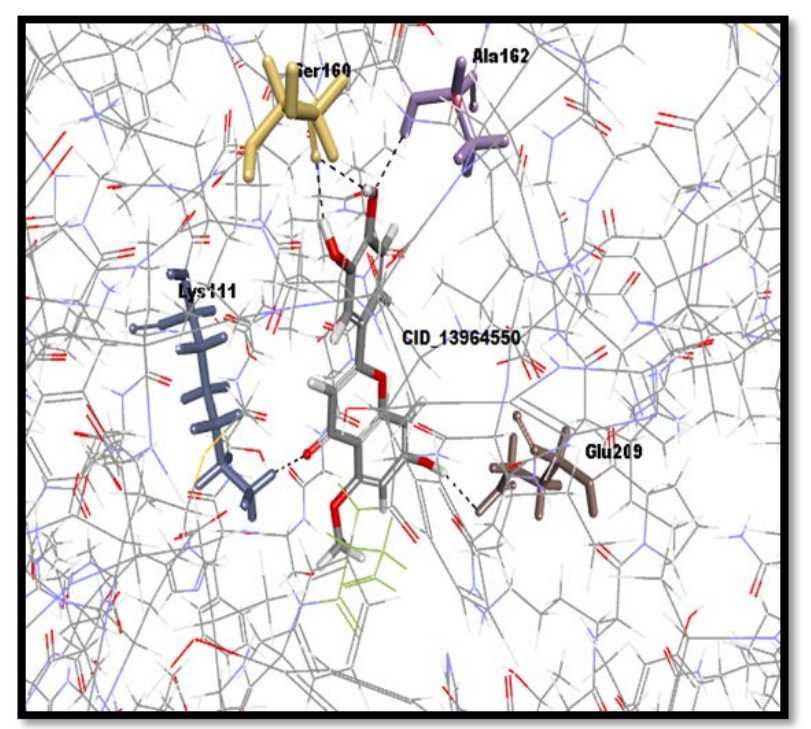

(d)

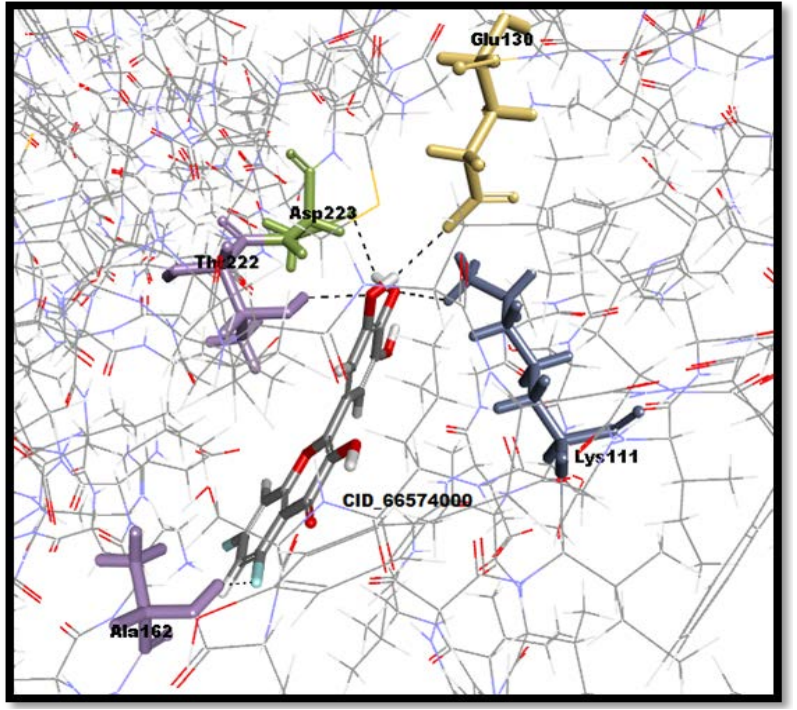

(e)

Figure 5. Molecular docking results of top hits.

present in the plant kingdom as a secondary metabolite. It is the most well defined group of polyphenolic compounds. Myricetin is commonly found as O-glycosides with one of its hydroxyl group are substituted by sugars of various types. Molecular docking study of all compounds within the active sites of the PDK-1 kinase was carried out using CDOCKER docking method implemented in Discovery studio 2.5. Molecular docking results of Myricetin and the top hits analogues were tabulated in Table 4. Docking energy of top ten docking hits were varies between -42.8 to $-35.6 \mathrm{kcal} / \mathrm{mol}$ (detailed in Table 4). Negative docking energy indicates a more favorable binding of ligand at the binding pocket of the PDK-1 kinase. The non-covalent interaction of small-molecule to the proteins is governed by a range of inter-atomic contacts. These are mainly electrostatic interaction as well as van der Waals interactions. Hydrogen bonding is one of the most essential type of interaction shown by the protein and ligand molecule. The residues most likely involved in formation of hydrogen bonds were Lys111, Ala 162, Ser 160, Glu 130, Thr 222 and Asp 223 in most of cases. Among these amino acid residues the Ala 162 and Ser 160 are the Hinge region's amino acid. Figure 5(e) depicts the molecular docking interactions of top hits with PDK-1 kinase. Molecular docking results revealed that all the analogues formed a stable complex within the active site of the PDK-1 kinase. It depicts that the screened analogues of Myricetin 
Table 4. Top ten docking hits of Myricetin and analogues.



CID_66574000<smiles>O=c1c(O)c(-c2cc(O)c(O)c(O)c2)oc2cc(F)cc(F)c12</smiles>

CID_6677685<smiles>O=c1cc(/C=C/c2ccc(O)c(O)c2)oc2cc(O)cc(O)c12</smiles>

CID_6677684<smiles>O=c1cc(/C=C/c2ccc(O)c(O)c2)oc2cc(O)ccc12</smiles>

$-38.98$

Docking Energy Kcal/mole

$-41$

$-42.8$

$-35.6$



CID_5322065

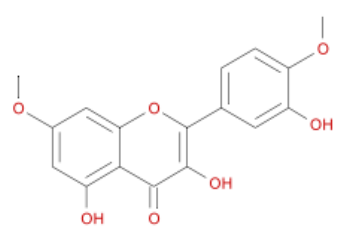

Hydrogen bonding Residues

Hydrogen Bond distances ( $\AA$ )
A:LYS111:HZ1 - 5281672:O5

A:LYS111:HZ3 - 5281672:O5

2.44

2.19

A:ALA162:HN -5281672:O8

5281672:H28-AGLU:OE2

5281672:H30-AASP223:OD1

5281672:H32 A:SER162:O

5281672:H33 A:SER162:O

2.34

2.31

2.09

2.14

1.98

A:LYS111:HZ3 - 66574000:O8 A:ALA162:HN - 66574000:F1 A:THR222:HG1 - 66574000:O7 66574000:H30 - A:GLU130:OE2 66574000:H31 - A:ASP223:OD1

A:LYS111:HZ2 - 6477685:O6 A:LYS111:HZ3 - 6477685:O6 A:ALA162:HN - 6477685:O4 6477685:H32 - A:ALA162:O 6477685:H34 - A:GLU130:OE2 6477685:H35 - A:ASP223:OD1

A:LYS111:HZ2 - 6477684:O5 A:LYS111:HZ3 - 6477684:O5

A:ALA162:HN - 6477684:O2 6477684:H33 - A:GLU130:OE2

A:LYS111:HZ3 - 57402278:O4 A:ALA162:HN - 57402278:O7 57402278:H39 - A:GLU90:O 57402278:H41 - A:SER160:O 


\section{Continued}

CID_5281701<smiles>O=c1cc(-c2cc(O)c(O)c(O)c2)oc2cc(O)cc(O)c12</smiles>

CID_10517292<smiles>O=c1c(O)c(-c2cc(O)c(O)c(O)c2)oc2ccccc12</smiles>

CID_13964550<smiles>COc1cc(O)cc2oc(-c3ccc(O)c(O)c3)cc(=O)c12</smiles>

A:LYS111:HZ3 - 5281701:O3 1.91 5281701:H28 - A:ASP223:OD1 5281701:H29 - A:GLU209:OE2 5281701:H31 - A:SER160:O

A:LYS111:HZ3 - 10517292:O5 10517292:H28 - A:GLU166:OE2 2.19 10517292:H29 - A:ASP223:OD2 2.33 10517292:H31 - A:ASP223:OD2 2.36 10517292:H29 - A:ASN210:OD1 1.92

A:LYS111:HZ3 - 13964550:O3 1.72 A:ALA162:HN - 13964550:O6 2.21 13964550:H32 - A:GLU209:OE2 2.14 13964550:H33 - A:SER160:O 1.87 13964550:H34 - A:SER160:O 2.22

A:LYS111:HZ3 - 5281697:O3 2.10 5281697:H29 - A:ASP223:OD1 2.35 5281697:H30 - A:GLU130:OE2 2.16 5281697:H31 - A:ALA162:O 1.93

can also act as a probable drug as PDK-1 kinase inhibitor.

\section{Conclusion}

It can be concluded that myricetin and the analogues have better binding interactions with PDK1 kinase (PDB: 1UU7.) The binding energies of the protein-ligand interactions also confirm that the ligands are fit into the active pockets of receptor tightly. Insilico ADMET study concludes that all the analogues have better profiles when compare with myricetin. These may held better potential as drug candidates that inhibit the PDK-1 kinase. Further development and modification of these analogues may lead to generation of novel high potent anticancer drug in future. 


\section{Acknowledgements}

The authors thank to UGC for providing financial support and GVK Biosciences Pvt., Ltd., for their cooperation and providing software facilities.

\section{References}

[1] Fabian, M.A., Biggs III, W.H., Treiber, D.K., Atteridge, C.E., Azimioara, M.D., Benedetti,M.G., Carter, T.A., Ciceri, P., Edeen, P.T., Floyd, M., Ford, M., Galvin, J.M., Gerlach, M., Gortzfeld, J.L., Herrgard, R.M., Insko, S., Insko, M.A., Lai, A.G., Lelias, J.M., Mehta, S.A., Milanov, Z.V., Velasco, A.M., Wodicka, L.M., Patel, H.K., Zarrinkar, P.P. and Lockhart, D.J. (2005) A Small Molecule-Kinase Interaction Map for Clinical Kinase Inhibitors. Nature Biotechnology, 23, 329-336. http://dx.doi.org/10.1038/nbt1068

[2] Manning, G., Whyte, D.B., Martinez, R., Hunter, T. and Sudarsanam, S. (2002) The Protein Kinase Complement of the Human Genome. Science, 298, 1912-1934. http://dx.doi.org/10.1126/science.1075762

[3] Akritopoulou-Zanze, I. and Hajduk, P.J., (2009) Kinase-Targeted Libraries: The Design and Synthesis of Novel, Potent and Selective Kinase Inhibitors. Drug. Drug Discovery Today, 14, 291-297. http://dx.doi.org/10.1016/j.drudis.2008.12.002

[4] Anderson, S.L., Stokoe, D., Erdjument-Bromage, H., Painter, G.F., Holmes, A.B., Gaffney, P.R., Reese, C.B., McCormick, F., Tempst, P., Coadwell, J. and PHawkins, T. (1998) Protein Kinase B Kinases That Mediate Phosphatidylinositol 3,4,5-Trisphosphate-Dependent Activation of Protein Kinase B. Science, 279,710-714. http://dx.doi.org/10.1126/science.279.5351.710

[5] Alessi, D.R., Deak, M., Casamayor, A., Caudwell, F.B., Morrice, N., Norman, D.G., Gaffney, P., Reese, C.B., MacDougall, C.N., Harbison, D., Ashworth, A. and Bownes, M. (1997) 3-Phosphoinositide-Dependent Protein Kinase-1 (PDK1): Structural and Functional Homology with the Drosophila DSTPK61 Kinase. Current Biology, 7, 776-789. http://dx.doi.org/10.1016/s0960-9822(06)00336-8

[6] Currie, R.A., Walker, K.S., Gray, A., Deak, M., Casamayor, A., Downes, C.P., Cohen, P., Alessi, D.R. and Lucocq, J. (1999) Role of Phosphatidylinositol 3,4,5-Trisphosphate in Regulating the Activity and Localization of 3-Phosphoinositide-Dependent Protein Kinase-1. Biochemical Journal, 337, 575-583. http://dx.doi.org/10.1042/0264-6021:3370575

[7] Kobayashi, T. and Cohen, P. (1999) Activation of Serum- and Glucocorticoid-Regulated Protein Kinase by Agonists That Activate Phosphatidylinositide 3-Kinase Is Mediated by 3-Phosphoinositide-Dependent Protein Kinase-1 (PDK1) and PDK2. Biochemical Journal, 339, 319-328. http://dx.doi.org/10.1042/0264-6021:3390319

[8] Kobayashi, T., Deak, M., Morrice, N. and Cohen, P. (1999) Characterization of the Structure and Regulation of Two Novel Isoforms of Serum- and Glucocorticoid-Induced Protein Kinase. Biochemical Journal, 344,189-197. http://dx.doi.org/10.1042/0264-6021:3440189

[9] Park, J., Leong, M.L., Buse, P., Maiyar, A.C., Firestone, G.L. and Hemmings, B.A. (1999) Serum and GlucocorticoidInducible Kinase (SGK) Is a Target of the PI 3-Kinase-Stimulated Signaling Pathway. EMBO Journal, 18, 3024-3033. http://dx.doi.org/10.1093/emboj/18.11.3024

[10] Pullen, N., Dennis, P.B., Andjelkovic, M., Dufner, A., Kozma, S.C., Hemmings, B.A. and Thomas, G. (1998) Phosphorylation and Activation of p70 ${ }^{\text {s6k }}$ by PDK1. Science, 279, 707-710. http://dx.doi.org/10.1126/science.279.5351.707

[11] Alessi, D.R., Kozlowski, M.T., Weng, Q.-P., Morrice, N. and Avruch, J. (1997) 3-Phosphoinositide-Dependent Protein Kinase 1 (PDK1) Phosphorylates and activates the p70 S6 Kinase in vivo and in vitro. Current Biology, 8, 69-81. http://dx.doi.org/10.1016/S0960-9822(98)70037-5

[12] Mora, A., Komander, D., van Aalten, D.M. and Alessi, D.R., (2004) PDK1, the Master Regulator of AGC Kinase Signal Transduction. Seminars in Cell Developmental Biology, 15, 161-170. http://dx.doi.org/10.1016/j.semcdb.2003.12.022

[13] Dahia, P.L. (2000) PTEN, a Unique Tumor Suppressor Gene. Endocrine-Related Cancer, 7, 115-129. http://dx.doi.org/10.1677/erc.0.0070115

[14] Sansal, I. and Sellers, W.R. (2004) The Biology and Clinical Relevance of the PTEN Tumor Suppressor Pathway. Journal of Clinical Oncology, 22, 2954-2963. http://dx.doi.org/10.1200/JCO.2004.02.141

[15] Cully, M., You, H., Levine, A.J. and Mak, T.W. (2006) Beyond PTEN Mutations: the PI3K Pathway as an Integrator of Multiple Inputs during Tumorigenesis. Nature Reviews Cancer, 6, 184-192. http://dx.doi.org/10.1038/nrc1819

[16] Brooks, B.R., Brucolleri, R.E., Olafson, B.D., States, D.J., Swaminathan, S. and Karplus, M. (1983) CHARMM: A Program for Macromolecular Energy, Minimization, and Dynamics Calculations. Journal of Computational Chemistry, 4, 187-217. http://dx.doi.org/10.1002/jcc.540040211

[17] Lipinski, C.A., Lombardo, F., Dominy, B.W. and Feeney, P.J. (2001) Experimental and Computational Approaches to 
Estimate Solubility and Permeability in Drug Discovery and Development Settings. Advanced Drug Delivery Reviews, 46, 3-26. http://dx.doi.org/10.1016/S0169-409X(00)00129-0

[18] (2009) Accelrys Discovery Studio 2.5. Accelrys, San Diego. http://www.accelrys.com

[19] Komander, D., Kular, G.S., Schüttelkopf, A.W., Deak, M., Prakash, K.R., Bain, J., Elliott, M., Garrido-Franco, M., Kozikowski, A.P., Alessi, D.R. and van Aalten, D.M. (2004) Interactions of LY333531 and Other Bisindolyl Maleimide Inhibitors with PDK1. Structure, 12, 215-226. http://dx.doi.org/10.1016/j.str.2004.01.005

[20] Wu, G.S., Daniel, H., Robertson, C.L. and Brooks III, M.V. (2003) Detailed Analysis of Grid-Based Molecular Docking: A Case Study of CDOCKER-A CHARMm-Based MD Docking Algorithm. Journal of Computational Chemistry, 24, 1549-1562. http://dx.doi.org/10.1002/jcc.10306

[21] Egan, W.J., Merz, K.M. and Baldwin, J.J. (2000) Prediction of Drug Absorption Using Multivariate Statistics. Journal of Medicinal Chemistry, 43, 3867-3877. http://dx.doi.org/10.1021/jm000292e

[22] Cheng, A.L. and Merz, K.M. (2003) Prediction of Aqueous Solubility of a Diverse Set of Compounds Using Quantitative Structure-Property Relationships. Journal of Medicinal Chemistry, 46, 3572-3580. http://dx.doi.org/10.1021/jm020266b

[23] Susnow, R.G. and Dixon, S.L. (2003) Use of Robust Classification Techniques for the Prediction of Human Cytochrome P450 2D6 Inhibition. Journal of Chemical Information and Computer Sciences, 43, 1308-1315. http://dx.doi.org/10.1021/ci030283p

[24] Dixon, S.L. and Merz, K.M., (2001) One-Dimensional Molecular Representations and Similarity Calculations: Methodology and Validation. Journal of Medicinal Chemistry, 44, 3795-3809. http://dx.doi.org/10.1021/jm010137f

[25] Ertl, P., Rohde, B. and Selzer, P. (2003) Fast Calculation of Molecular Polar Surface Area as a Sum of Fragment-Based Contributions and Its Application to the Prediction of Drug Transport Properties. Journal of Medicinal Chemistry, 43, 3714-3717. http://dx.doi.org/10.1021/jm000942e

[26] Waterbeemd, H., Van de Smith, D.A. and Jones, B.C. (2001) Lipophilicity in PK Design: Methyl, Ethyl, Futile. Journal of Computer-Aided Molecular Design, 15, 273-286. http://dx.doi.org/10.1023/A:1008192010023

[27] Xia, X.Y., Maliski, E.G., Gallant, P. and Rogers, D. (2004) Classification of Kinase Inhibitors Using a Bayesian Model. Journal of Medicinal Chemistry, 47, 4463-4470. http://dx.doi.org/10.1021/jm0303195

[28] Ong, K.C. and Khoo, H.E. (1997) Biological Effects of Myricetin. General Pharmacology, 29, 121-126 http://dx.doi.org/10.1016/S0306-3623(96)00421-1

[29] Ross, J.A. and Kasum, C.M. (2002) Dietary Flavonoids: Bioavailability, Metabolic Effects, and Safety. Annual Review of Nutrition, 22, 19-34. http://dx.doi.org/10.1146/annurev.nutr.22.111401.144957 